\title{
Organizar na era dos sistemas: as contribuições críticas de Ivan Illich aos estudos organizacionais
}

\author{
LUCAS CASAgRANDE ${ }^{1}$ \\ Nilo CoRAdini de Freitas ${ }^{2}$ \\ 1 Universidade Federal do Rio Grande do Sul (UfRGS) / Escola de Administração, Porto Alegre - RS, Brasil \\ ${ }^{2}$ Universidade Federal do Rio Grande do Sul (UfrgS) / Programa de Pós-Graduação em AdministraçÃo, Porto Alegre - RS, Brasil
}

\begin{abstract}
Resumo
Este artigo apresenta a crítica de Ivan Illich à institucionalização na sociedade moderna, seu desenrolar na era dos sistemas e os problemas dela decorrentes por conta de suas escolhas tecnológicas. O objetivo é apresentar o pensamento do autor e suas contribuições aos estudos organizacionais. Para tal, adotou-se um formato ensaístico, visando a demonstrar as contribuições do autor e seus possíveis diálogos com a área. Assim, apresenta-se a ideia de desequilíbrio institucional, correlacionando-a com o conceito de ferramentas manipulativas em oposição a ferramentas conviviais. Nesse sentido, assume-se a técnica como não sendo neutra. Em seguida, aborda-se como a sociedade industrial reifica o ser humano e, nesse processo, transforma-se em um grande sistema social funcional, um corpo com órgãos, necessitando das instituições escola e saúde, além da indústria. Ela cria profissões incapacitantes que especializam os indivíduos até sua plena alienação e mediação. Por fim, incorpora um sistema de vigilância em massa na subjetividade de cada um. Diante disso, diferentes proposições são possíveis, como em Giorgio Agamben, de retirar o poder e desconstituir regras.
\end{abstract}

Palavras-chave: Ivan Illich. Convivialidade. Era dos sistemas. Organizações alternativas. Desinstitucionalização.

\section{Organizing in the Age of Systems: Ivan Illich's critical contributions to Organization Studies}

\begin{abstract}
This essay presents Ivan Illich's critique of institutionalization in modern society and its evolution to the Age of Systems, the problems that arise, and its imbrication with technological choices. The essay explores the author's thoughts and the contributions of his dialogues to the Organization Studies. The study presents the idea of institutional imbalance and correlates it with the concept of manipulative tools as opposed to convivial tools, assuming, therefore, that technique is not something neutral. The study then discusses how industrial society reifies the human being and becomes a great functional social system, a 'body with organs,' which needs the institutions 'school,' 'health', and industry. Industrial society creates disabling professions that specialize individuals until their full alienation and mediation, and it incorporates a system of mass surveillance in the subjectivity of each one. Against this, different propositions of withdrawing power, or deconstructing rules are possible, as shown by Giorgio Agamben.
\end{abstract}

Keywords: Ivan Illich. Conviviality. Age of Systems. Alternative Organizations. Institutionalization.

\section{Organizar en la era de los sistemas: contribuciones críticas de Iván Illich para los estudios organizacionales}

\section{Resumen}

El artículo presenta la crítica de Ivan Illich a la institucionalización en la sociedad moderna y su desarrollo en la Era de los Sistemas y los problemas derivados de ésta debido a las elecciones tecnológicas. Se pretende presentar el pensamiento del autor y sus contribuciones al área de Estudios Organizacionales. Para ello, se adoptó un formato ensayístico, buscando demostrar las contribuciones del autor y sus posibles diálogos con el área. Así, se presenta la idea de desequilibrio institucional y se la correlaciona con el concepto de herramientas manipulativas en oposición a herramientas convivenciales. Para tal, se asume la técnica como no siendo neutra. A continuación, se aborda cómo la sociedad industrial reifica al ser humano y, en ese proceso, se transforma en un gran sistema social funcional, en un cuerpo con órganos, para lo que necesita las instituciones escuela, salud e industria. Crea profesiones incapacitantes que especializan a los individuos hasta su plena alienación y mediación. Finalmente, incorpora un sistema de vigilancia masiva en la subjetividad de cada uno. Frente a eso, son posibles diferentes proposiciones, como en Giorgio Agamben, de retirar el poder y suprimir reglas.

Palabras clave: Ivan Illich. Convivencialidad. Era de los Sistemas. Organizaciones alternativas. Desinstitucionalización. 
Essa crise está enraizada em um grande experimento duplo que fracassou, e afirmo que a solução da crise começa com o reconhecimento do fracasso. Porcem anos, tentamos fazer com que as máquinas trabalhassem para os homens e escolarizá-los para a vida toda, a serviço delas. Agora, acontece que as máquinas não trabalham e que as pessoas não podem ser escolarizadas por toda a vida para servir as máquinas. A hipótese sobre a qual o experimento foi construído deve agora ser descartada (ILLICH, 1973a, p. 23, tradução nossa).

\section{INTRODUÇÃO}

Era uma noite animada na casa do embaixador canadense no Irã. Jantavam à mesa o então embaixador James George, Peter Lamborn Wilson e Ivan Illich. O contexto nacional em 1974 era de um liberalismo prévio à revolução religiosa iraniana. Chegara um telegrama remetido pelo recém-eleito governador da Califórnia, Jerry Brown, a Ivan Illich. Ao ler a missiva, Illich, que tinha um temperamento tão calmo que Ihe rendeu uma aura de santidade, desatou-se a praguejar enfurecido. Esse comportamento já seria suficiente para gerar estranhamento aos presentes, mas o conteúdo do telegrama tornou tudo ainda mais curioso (BEY, 2008).

Ocorre que o telegrama era um convite para que Ivan Illich fosse à Califórnia para assumir um alto posto na administração do estado. Junto a isso, encontrava-se o convite para aparecer na TV, oferecendo uma face pública e amigável às políticas de governo, e para voar até os Estados Unidos da América (EUA) às custas de Jerry Brown. Os colegas de mesa, desconcertados, pediram que Illich explicasse as razões de sua fúria. Ocorre que: a) Illich tinha pavor de voar e só estava ali em Teerã porque o convite de seus comensais "estava cheio de erros de digitação" ${ }^{1}$; b) Illich entendia que a mídia não era uma instituição a ser reformada porque, por definição, torna objetivo o que é inerentemente subjetivo; e c) ele não queria reformar o Estado e suas instituições, mas sim vê-las ruir diante de outras formas de organização - de modo que fazer parte da administração do Estado da Califórnia se mostrava algo absurdo e contrário às suas convicções pessoais (BEY, 2008).

Mas sua indignação residia no fato de que sua subjetividade, atrelada reconhecidamente à contracultura, sofria um ataque, uma tentativa de cooptação. De fato, para Illich, não seria possível resolver problemas tornando o Estado mais aberto, pois o problema da educação, por exemplo, não consistia na ineficiência das escolas, em seu elitismo ou, como em Paulo Freire (1987), em uma pedagogia que vê o aluno como utilizador de um serviço no qual deve manter-se passivo. O problema era que a escola, "vaca sagrada" tanto da direita quanto da esquerda, era (e é) uma ferramenta de hierarquização social e de dominação, atrelada ao desenvolvimentismo que advoga o crescimento econômico como forma última de fugir aos conflitos sociais. A escola moderna é, por definição, uma instituição ferramental para um projeto de exploração da natureza e das pessoas.

Neste artigo, almejamos demonstrar como o pensamento de Illich é vasto e como sua teoria tem potencial para entender melhor a relação entre organizações, sociedade e técnica. Illich escreveu, ao longo de sua vida, sobre instituições que, como a escola, pass(av)am a se autoperpetuar para atender às suas próprias necessidades, em detrimento dos propósitos para os quais foram criadas em primeiro lugar. O pensamento de Illich proporciona um rico material, expondo uma visão da articulação entre tecnologia, autoridade e instituições e destas nas diferentes possibilidades organizacionais e de equidade social. Ele via como a utilização de determinadas ferramentas viria a fomentar diferentes relações sociais e, com elas, diferentes subjetivações. A partir desse marco teórico fundamental, moveremo-nos para tratar da crítica ao industrialismo e ao desenvolvimento. 0 modo de vida industrial mina a capacidade das populações postularem suas necessidades de outra forma que não por meio da demanda por produtos industriais que jamais poderiam atender a todas as pessoas (ou a todas as necessidades), sendo estas incessantemente criadas, de modo a atrofiar a capacidade de solucionar os problemas por outras formas. Para Illich, nossa era dá origem ao homo miserabilis, aquele que se tornou tão alienado e mediado pela sociedade industrial que sua vida se prendeu a um eterno ciclo de criação e suprimento de necessidades.

A partir disso, trataremos da crítica ao prometeísmo inerente às organizações burocráticas. Para Illich, o discurso técnico presente no cientificismo moderno, base da burocracia, se mostra ingênuo ao acreditar na liberdade humana por meio da sujeição das máquinas. Na verdade, o autor percebeu que a sujeição contrária foi aquilo que de fato ocorreu no experimento moderno,

\footnotetext{
${ }^{1}$ Para além da questão anedótica, o medo de Illich não era só uma fobia. Como o autor aponta em "Energia e Equidade" (ILLICH, 2005), o uso intensivo de energia impede a equidade social. A alta velocidade com que uma parcela da sociedade se move, decorre da distorção do espaço, transformando o convívio social em infraestrutura para a alta velocidade.
} 
por meio do que denominou ferramentas manipulativas. Dessa forma, trataremos da ideia de desequilibrio institucional e da noção de ferramenta do autor.

Com essa base teórica bem estabelecida, trataremos das instituições que Illich se dedicou a denunciar: a educação institucionalizada, a saúde e o trabalho. Para tal, recorremos a seus pensamentos relativos à educação para demonstrar como está se limita a ser um instrumento do desenvolvimentismo. Apesar de Illich e Paulo Freire terem sido bons amigos e nutrirem uma parceria, seus pensamentos são, por vezes, antagônicos. Já no ramo médico, Illich denunciava como a institucionalização delegou o corpo ao profissional, ao médico. Perdeu-se autonomia e criou-se um custo gigantesco em proveito de uma técnica que trouxe menos benefícios à vida do que se propaga. A mesma lógica se deu no trabalho: a sociedade moderna transformou a criação em trabalho incapacitante, a produção do novo em reprodução do mesmo.

Tal reprodução, com o passar do tempo, foi adquirindo uma tonalidade de introjeção dos papéis sociais. Aquilo que antes era atribuído pelas instituições modernas passou, paulatinamente, a ser introjetado nos sujeitos. Essa quebra entre instituição e sistema marca a ruptura do pensamento de Ivan Illich nos anos 1980, quando deixa de enfocar as instituições modernas e passa a se dedicar à introjeção dos papéis cibernéticos da sociedade nos indivíduos. Dessa forma, a vida é reduzida ao papel, a criação ao trabalho incapacitante e as relações sociais ao sistema social. Tudo isso mediado por ferramentas manipulativas, pela técnica moderna e pela burocracia. Trata-se do que o autor chamou de era dos sistemas.

Por fim, delinearemos preliminarmente as alternativas do autor. Tratam-se das ferramentas conviviais, da celebração da vida e do epimeteanismo em oposição à visão prometeica (enquanto amor à técnica por si). Concluímos que a obra de Ivan Illich apresenta importantes contribuições aos estudos organizacionais e entra em diálogo com vários autores da área, podendo corroborar e aprofundar reflexões já existentes.

\section{O DESEQUILÍBRIO INSTITUCIONAL E A NOÇÃO DE FERRAMENTA EM IVAN ILLICH}

Da mesma forma que a iatrogênese - a doença criada pela própria intervenção médica - constitui um problema amplamente desconsiderado na sociedade moderna, o uso das ferramentas que não satisfazem os problemas que se supõe que deveriam satisfazer e ainda criam novos problemas também não é levado em conta. Obviamente, tal consideração não é nova, embora seja necessário estabelecê-la em ampla escala. Os antigos gregos contavam a história de Prometeu, um titã que roubou as ferramentas (o "fogo") dos deuses do Olimpo para distribuí-las aos seres humanos. Como sentença irônica por seu crime, esse titã - um ser imortal - foi condenado a ter seu fígado devorado todos os dias por uma grande águia. Seu fígado imortal estaria novo no dia seguinte - mas sua punição se repetiria. A horrível pena do titã pode ser interpretada como uma punição adequada ao mal que ele gerou: possibilitou que os seres humanos obtivessem ferramentas que, ao ser utilizadas para resolver antigos problemas, gerariam outros, eternamente.

Para Illich, o avanço das soluções industriais se baseava em uma premissa: a de que seria possível substituir escravos por máquinas. No entanto, tal premissa se mostrou falsa. A tentativa de desenvolver soluções nessas bases acarretou a hipertrofia de aparelhos burocráticos que moldaram o mundo às suas dimensões, em detrimento das dimensões humanas, causando estranhamento às pessoas e dependência em relação a tais aparelhos. A maior parte das agências sociais reorganizadas pela ciência passou por esse processo.

A princípio, novo conhecimento é aplicado para a solução de um problema claramente declarado e uma mensuração científica é feita para demonstrar a nova eficiência. Mas em um segundo ponto, o progresso demonstrado no feito anterior é utilizado para a exploração da sociedade como um todo em serviço de um valor o qual é determinado e constantemente revisado por um elemento da sociedade, por uma de suas elites autocertificadas (ILLICH, 1973a, p. 7, tradução nossa).

O pensamento de Illich se pauta por uma categoria central: a ferramenta. Esta, sinônimo daquilo que muitos autores denominam tecnologia, é um conceito da topografia mental moderna que funda um meio pelo qual os seres humanos tentam alcançar seus objetivos. Dito de outra forma, ferramenta é o conceito moderno que abarca os meios para expressar intenções humanas, sejam elas quais forem. Tal conceito, posto dessa forma ampla, possibilita abarcar não apenas equipamentos, mas também organizações. 
As ferramentas podem dividir-se em duas categorias, como o autor propõe: a) manejáveis ${ }^{2}$; ou b) manipuláveis ${ }^{3}$. As primeiras são aquelas que adaptam a energia de uma pessoa para uma tarefa específica, como, por exemplo, uma caneta, um martelo, uma faca, roldanas, ou para tarefas mais complexas, como um tear manual ou uma bicicleta. As ferramentas manejáveis também podem ser muito complexas, como um sistema de ciclovias com estações de reparos utilizado por bicicletas e riquixás. Já as ferramentas manipuláveis requerem energia externa ao ser humano. Pode ser o boi que ara a terra, o cavalo no qual se encilha ou ferramentas mais complexas, como o automóvel e, ainda, coisas que hoje tratamos como triviais - basicamente tudo o que ligamos na tomada.

O predomínio de ferramentas manejáveis, aquelas que não requerem energia externa a nós, permite que os habitantes de determinada comunidade ajam mais criativamente. Em tal situação, as ferramentas são conviviais. A relação oposta, típica da modernidade industrial, produz um domínio das ferramentas manipuláveis, que passam a subjugar as manejáveis. Nessa situação, as ferramentas são manipulativas. Resumidamente, a maior intensidade das ferramentas manipuláveis produz uma relação de dominação técnica sobre as manejáveis, manipulando-as e, junto com elas, as pessoas que utilizam as ferramentas manejáveis. Por fim, nesse processo de dominação, o homem que maneja ferramentas se torna o boi que puxa o arado para outrem.

A tipologia ferramental de Illich gera, por decorrência, duas esferas de produção: a) uma autônoma; e b) outra heterônoma. A autônoma é a esfera de produção material com predomínio das ferramentas manejáveis. Já a esfera heterônoma de produção é aquela que opera por meio da divisão e da especialização do trabalho e de produtores e consumidores. Ela opera via mercado e requer um complexo aparato de instituições para formar, garantir e fiscalizar especialistas. Por fim, cada qual opera um universo pré-definido da produção social e a divisão do trabalho horizontal, mediante especialistas, acaba por requerer uma divisão do trabalho vertical, via chefia e concentração dos meios de produção, ou seja, das ferramentas.

Cada um dos produtos industriais resulta de uma forma de produção cara em capital investido, seja em material ou em saber. "Cada um desses produtos concorre com um valor de uso que as pessoas desfrutaram sempre de maneira autônoma" (ILLICH, 1975a, p. 66). Os bens produzidos autonomamente são, por natureza, impossíveis de ser alienados em um mercado, produzidos para venda, e não aparecem no PIB, na maior parte do tempo, não são atividades realizadas por dinheiro e, na maioria das vezes, não podem ser. $\mathrm{O}$ autor buscou estudar o estrangulamento da forma autônoma de produção pelo avanço da heteronôma, sem demonizar o industrialismo: "sem dúvida o produto industrial pode tornar a ação mais eficaz e o ator mais independente. É o caso das bicicletas, dos livros e dos antibióticos, que além disso podem ser produzidos mais eficazmente de uma forma industrial" (ILLICH, 1975a, p. 68). Portanto, há uma noção de que pode haver sinergia entre ambas as formas de produção, embora se perceba um desequilíbrio em favor do modo heterônomo, que leva a produção total a uma contraprodutividade, uma vez que certo limiar de produção seja ultrapassado. Tal limiar ocorre quando um progresso obtido anteriormente se converte em meio de explorar o conjunto social para colocá-lo a serviço de uma elite especializada ${ }^{4}$.

O desequilíbrio propiciado pelo avanço das instituições burocráticas e industriais, resultantes da preponderância da esfera heterônoma de produção, foi visto por Illich (1973a) como prejudicial por 6 motivos:

1) Degradação biológica;

2) Monopólio radical;

3) Superprogramação;

4) Polarização de poder;

5) Obsolescência; e

6) Frustração.

\footnotetext{
${ }^{2}$ Manejáveis é o termo utilizado na versão em língua portuguesa (ILLICH, 1976). Illich, como um poliglota, escrevia seus livros em diversas línguas. A obra referida, intitulada "tools for conviviality" (ILLICH, 1973a), em inglês, ou "Ia convivialité" (ILLICH, 1973b), em francês, foi redigido, diretamente, em pelo menos esses dois idiomas. Nesta última versão, o conceito é denominado "outil maniable", traduzido para o italiano como "strumento maneggiabile" (ILLICH, 1974c) e para o espanhol como "herramienta manejable" (ILLICH, 1974b), e parece-nos mais condizente a aplicação adotada em português: ferramenta manejável. No entanto, na versão em inglês, escrita diretamente pelo autor, consta como "hand tool", o que difere levemente.

${ }^{3}$ Manipuláveis é o termo utilizado na versão em língua portuguesa (ILLICH, 1976). Tal conceito aparece na versão original em francês como "outil manipulable", traduzido daí para o italiano "strumento manipolabile" e para o espanhol "herramienta manipulable". No entanto, tal como o conceito anterior, em inglês aparece distintamente como "power tools". Novamente, a opção foi pela raiz gramatical latina ao definir o conceito em português.

${ }^{4} \mathrm{O}$ limiar referido se trata do momento em que as ferramentas manipuláveis se tornam dominantes como meios para atingir fins, gerando um processo contínuo de especialização tautológica, "ao começar a decrescer a utilidade marginal do aumento da especialização quantificável em termos de bem-estar coletivo" (ILLICH, 1974b, p. 16, tradução nossa).
} 
O autor entendia que o uso da tecnologia poderia acabar por tornar o ambiente inabitável, o que já era certo lugar-comum na década de 1970. O monopólio radical não é aquele de determinada empresa em certo mercado, mas a exclusividade de determinada solução industrial a uma necessidade humana, excluindo soluções não industriais. Por exemplo, uma cidade desenhada em função do automóvel individual pode proporcionar a esse produto um monopólio radical, impossibilitando que outras formas de transporte sejam postas em prática de modo efetivo.

Superprogramação é um descompasso no aprendizado das pessoas no qual saberes programados - típicos da escolarização sobressaem-se a saberes desenvolvidos a partir de observação e participação. Em um mundo superprogramado, a realidade induz os comportamentos aceitáveis e aqueles não aceitáveis, tal como em um hospício comportamental, onde todos são constantemente "ensinados, socializados, normalizados, testados e reformados" (ILLICH, 1973a, p. 83). Tal programação condiciona os indivíduos a negar seus próprios sentidos em prol da norma, da "verdade", da ciência, da autoridade enunciativa. A superprogramação é o que, nos termos de Marcuse (1991), unidimensionaliza o homem em uma única forma de lidar com a realidade. De fato, Illich (1973a), em claro diálogo com Herbert Marcuse, aponta que, como forma de multidimensionalizar, é necessário considerar os seis aspectos mencionados acima.

De modo semelhante, Guerreiro Ramos (1989) percebeu que a síndrome comportamentalista reduz a legitimidade de qualquer pensamento e ação à sua conformidade utilitária diante do comportamento e regramento alheio. A polarização se dá com o desenvolvimento das megamáquinas, à medida que se impõe no quotidiano dos povos e necessita de elites capacitadas para geri-las, impossibilitando uma distribuição equitativa de poder. Na obra de Guerreiro Ramos (1989, p. 150, tradução nossa) se aponta como solução para tal problema a ideia de isonomia, que consistiria em um "contexto em que todos os membros [de uma comunidade] são iguais". Essa ideia, o autor admite, é inspirada em autores anteriores, como o próprio Ivan Illich, que propunham "instrumentos necessários para essa reconstrução social, que Illich denominara 'convivial'” (GUERREIRO RAMOS, 1989, p. 151).

Por fim, a obsolescência diz respeito à necessidade de constante renovação dos produtos requeridos para o funcionamento das burocracias e da sociedade sob seu jugo, como peças, máquinas e diplomas. Em cada uma dessas dimensões, as ferramentas podem tornar inviável que a maioria das pessoas se relacione com e aja no ambiente à sua volta, gerando frustração.

O gerencialismo faz parte desse processo, difundindo a ideia de que as organizações burocráticas formais, sendo as mais eficientes, constituem a melhor forma de alcançar objetivos organizacionais, modelando os estudos organizacionais como uma ciência social aplicada - conforme o positivismo e a ciência se tornaram mais poderosos nas décadas de 1950 e 1960 (MARSDEN e TOWNLEY, 2001).

O gerencialismo pode ser visto como uma abordagem ao problema da governança que naturaliza as relações capitalistas como inevitáveis por meio de uma combinação de ideologia e tecnocracia, fomentando um relato progressista do mundo moderno, embasado nas promessas da tecnologia, na escolha, na abundância e na riqueza (PARKER, 2018).

A crítica illichiana também se desdobrou, de modo a chegar ao chamado "desenvolvimento". Latouche (2012, p. 4-5) salienta que

[...] toda a obra de Illich consiste em pôr em xeque o desenvolvimento, o crescimento econômico, a industrialização com sua técnica heterônoma e o modo de vida moderno, mas ele nunca faz a crítica frontalmente, e sim através da análise das instituições e das transformações.

Para Illich (1977b), o subdesenvolvimento consiste em haver cada vez mais pessoas com cada vez menos escolhas, isto é, um duplo processo de aumento populacional e de industrialização referenciada a partir dos chamados países desenvolvidos. Illich via as nações ricas transformando suas máquinas de guerra em programa de desenvolvimento para o chamado terceiro mundo, como forma de "pacificá-lo" economicamente. Enormes instituições produzindo serviços custosos dominam os horizontes de nossa inventividade:

Quanto mais o cidadão é treinado no consumo de bens e serviços empacotados, menos efetivo ele parece se tornar em moldar seu ambiente. Suas energias e finanças são consumidas procurando novos modelos de seus grampos, e o ambiente torna-se um subproduto de seus hábitos de consumo (ILLICH, 1977b, p. 56, tradução nossa).

Assim, as nações desenvolvidas impunham "benevolentemente" uma camisa de força de engarrafamentos, confinamentos hospitalares e salas de aula às nações pobres e denominavam isso, via acordo internacional, "desenvolvimento" (ILLICH, 
1977b). "A explosão populacional oprime a imaginação, mas a atrofia progressiva da imaginação social é racionalizada como uma escolha entre marcas" (ILLICH, 1977b, p. 59, tradução nossa), ambos os processos convergindo para produzir mais consumidores, enquanto as imaginações se tornam incapazes de encontrar soluções diferentes das industriais para suas necessidades. $O$ uso do gerencialismo é evidenciado, por exemplo, na Administração e Gestão do Desenvolvimento (AGD), adotada por agências internacionais como o Banco Mundial como ferramenta na intervenção de nações ricas no chamado "terceiro mundo", levando ao estabelecimento de uma ordem econômica neoliberal particular (COOKE, 2004).

Illich também postulava o subdesenvolvimento como um "estado de espírito" ou uma forma de consciência na qual só é possível imaginar soluções impossíveis de ser alcançadas pela maioria. Isso ocorre por meio da reificação (Verdinglichung): a percepção de verdadeiras necessidades transformada, embrutecida, na demanda de mercadorias produzidas em massa. "Este tipo de reificação ocorre na manipulação de necessidades humanas primárias por vastas organizações burocráticas que foram bem-sucedidas em dominar a imaginação de consumidores potenciais" (ILLICH, 1977b, p. 60, tradução nossa). Nesse processo, o gerencialismo atribui necessidades aos seres humanos por meio de uma ferramenta analítica denominada "comportamento organizacional", postulando que as pessoas "calculam suas preferências e fazem decisões sobre ação de acordo com elas", muito similarmente ao homo oeconomicus que Parker (2018, p. 35, tradução nossa) denomina "egoístas racionais". Assim, tem-se a perda do vernáculo e da autonomia e a manufatura das necessidades, que são contínua e necessariamente frustradas. O princípio geral da contraprodutividade fora explorado mais a fundo teoricamente nos âmbitos da educação, da saúde e do trabalho, que comentamos a seguir.

\section{CORPO COM ÓRGÃOS: DA DEPENDÊNCIA DAS INSTITUIÇÕES À CIBERNÉTICA}

A obra de Illich permite depreender que a sociedade moderna é um projeto de dominação sob o pretexto de funcionalidade e produtivismo posto em prática via ferramentas manipulativas. Sob o argumento de maior eficiência, passa-se a escravizar a natureza e os próprios seres humanos. Para tal, é necessário criar exércitos especializados, profissionais capazes de exercer suas atribuições, mesmo que pequenas e específicas. Com isso, atribui-se um sentido de eficiência ao sistema social e, sob tal égide, legitima-se a exclusividade do exercício profissional especializado, criando uma dependência das pessoas diante desses especialistas.

Tal processo de especialização supostamente eficiente e de atribuição do trabalho cria, por um lado, a outorga da própria vida ao profissional e, por outro, insere todos em um projeto de profissionalidade total. Tornamo-nos órgãos que interagem em um grande corpo social, tal como na metáfora de Durkheim (1977), no qual a vida humana se torna parte do sistema social, onde este assume primazia sobre aquela. Esse corpo com órgãos necessita de uma série de processos institucionais de reificação do corpo humano, como a escola, o hospital e a indústria, como veremos a seguir.

\section{Desinstitucionalizando a educação}

O título da obra mais famosa de Illich, recentemente relançado no Brasil pela Editora Vozes (ILLICH, 2018), Sociedade sem escolas, é uma provocação por si i $^{5}$ Trata-se de um clamor por abandonar a ideia de que a escola, enquanto instituição, resolve os problemas sociais - que é a transposição da ideia de que a educação (enquanto valor substantivo) emanciparia a humanidade. Illich nota que há um profundo hiato entre escola e educação: a institucionalização de algo não o torna onipresente e pode, ainda, transformar o valor em um conjunto de regras que transpõe meios a fins. Senão, note-se como o judiciário se apropria do valor justiça em prol de sua própria legitimidade - ao passo que o próprio Poder Judiciário se transmutou na nossa novilíngua ${ }^{6}$ em "Justiça". Por certo, o mesmo ocorre com a educação: educar-se é algo diferente de ser ensinado.

Sua crítica é ecoada em autores consagrados dos estudos organizacionais no Brasil, como Tragtenberg (2002, p. 2): "na instância das faculdades de educação, forma-se o planejador tecnocrata a quem importa discutir os meios sem discutir os fins da educação, confeccionar reformas estruturais que na realidade são verdadeiras 'restaurações'".

\footnotetext{
${ }^{5}$ Há uma discussão a respeito do título exato da obra de acordo com as diferentes edições. A Editora Vozes lançou a tradução em língua portuguesa como "Sociedade sem Escolas", a partir da versão francesa (Une société sans École), ao passo que a Editora Deriva lançou sua tradução como "Sociedade Desescolarizada" (ILLICH, 2007), a partir do original em inglês (Deschooling Society).

${ }^{6}$ Referência à obra de George Orwell (2010).
} 
Illich (1975b) evidencia que a escola, enquanto 'vaca sagrada', é a instituição que substitui a Igreja nos tempos atuais. No lugar da penitência eclesiástica temos a avaliação escolar. No lugar dos sermões, as aulas. Substituímos os ritos de passagem (batismo, comunhão, crisma etc.) por diplomas e certificados. E tal como os perversos que frequentam as igrejas substituindo ética por perdão institucional, a escola se tornou aquela que abençoa os ignorantes, os antiéticos e os supressores da vida alheia, desde que cumpram os requisitos formais escolares.

Evidentemente, será difícil obter instrução de uma escola que recusa educar a não ser que seus alunos se submetam ao mesmo tempo à sua tutela, a uma estéril competição e a uma doutrinação. É difícil, evidentemente, financiar um professor considerado simultaneamente como um guardião, um árbitro, um conselheiro e o diretor dos currículos. É antieconômico combinar estas funções numa única instituição. É precisamente a fusão destas quatro funções, frequentemente antitéticas, que eleva o custo da educação transmitida pela escola. É esta igualdade a causa da nossa crônica escassez de recursos educacionais (ILLICH, 1975b, p. 108). ${ }^{7}$

Embora Illich e Paulo Freire tenham tido suas desavenças teóricas, havia um profundo respeito mútuo - a ponto de Paulo Freire ter ido diversas vezes a Cuernavaca, onde Illich trabalhara (SILVA, 2016), bem como de Illich ter vindo algumas vezes ao Brasil (ILLICH, 1975c), inclusive sendo uma dessas vezes para "obter o desencarceramento [...] de Paulo Freire" após o golpe de 1964 (MILANA, 2008, p. 133). Segundo Mesquida (2007), os dois autores contemporâneos partiam de uma preocupação teórica e prática com a opressão dos povos latino-americanos. A despeito de seus embates, identificam-se entre si enquanto pares do mesmo lado de uma trincheira. Ademais, como notam Estimado e Santos (2014), Illich não estava, de fato, advogando o fim da escola, mas a supressão da instituição escolar enquanto norteadora da vida humana. Deveríamos tornar a educação um instrumento humano - e não o oposto. Tal distinção é sutil, mas se mostra imprescindível na discussão de Illich: por certo, necessitamos de espaços para produzir e difundir o conhecimento. Mas esses espaços não podem ser tomados por tecnocratas, tampouco podem ser reduzidos a currículos, expedientes, atribuições, cargas horárias, e assim por diante. Afinal, isso é mais do que contraproducente: trata-se da subversão, no pior sentido da palavra, de um valor em um conjunto de regras.

Dessa forma, Illich e Freire estavam de acordo que as instituições, tal como se apresentavam, eram mais danosas do que benéficas à sociedade. Freire $(1980$, p. 7) afirma que a "instituição em si, portadora de uma natureza imutável da qual se diga é boa, é má [de forma que] a escola não existe [...] a escola está sendo historicamente". Ao passo que Freire situava a escola como subsistema social subjugado às classes dominantes, mas que, todavia, poderia ser reformada para produzir o movimento histórico oposto, Illich iria além em sua crítica, abandonando a ideia de reformismo da instituição. Notara ele que toda instituição escolar tem como definidor de seu modus operandi os processos de seleção e exclusão social. De fato, poucos dos que frequentam as escolas apreendem o que ali é apresentado. Também há, notou Illich, um fator ideológico de seleção; Paulo Freire, por sua vez, subverteu tal fator ideológico, tornando o tecnicismo burguês uma política dos oprimidos. Illich, no entanto, notou que havia algo de especial nisso, mas também percebeu que o processo de seleção e exclusão se mantinha, mas dessa vez voltado contra o público que não estava disposto a debater, pensar a comunidade ou promover melhorias coletivas:

Jamais esquecerei um serão passado com os alunos de Freire, esfomeados camponeses de Sergipe, no início de 1964. Um homem levantou-se, lutou para encontrar as palavras e finalmente conseguiu formular numa frase a conclusão a que pretendo chegar neste artigo: "eu não consegui dormir a noite passada... porque na véspera tinha escrito o meu nome... e compreendi então que eu sou eu... isto quer dizer que nós somos responsáveis" (ILLICH, 1975c, p. 124).

Dessa forma, concluiu Illich, se a instituição perdura, que ao menos seja moldada para quem se torne responsável por seus pares. Que se a escola exista, que ela seja política e que derive dos anseios de seus integrantes. Assim, talvez um dia sua própria subversão possibilite que a superemos. Talvez deixemos de ser humanos com necessidades providas por instituições e seus tecnoburocratas e passemos a ser seres plenos, generalistas-situacionistas (como Debord (2011) conceitua). Ou seja, que sejamos ao mesmo tempo artistas, técnicos, pintores, médicos de nós mesmos e autodidatas. Por ora, a formação em separado de cada profissão estrutura a sociedade para o trabalho incapacitante.

\footnotetext{
${ }^{7}$ Não confundamos aqui a crítica illichiana com um apelo à austeridade liberal ou ao combate ao "marxismo cultural" (sic). As desescolarizações vão no sentido da abolição da escola seriada, por exemplo, como a Escola da Ponte de José Pacheco e encontram exemplos históricos em experiências ligadas à esquerda libertária como A Colméia de Sébastien Faure (2015) e a lasnaia Poliana de Tolstói (ver CODELLO, 2007). Veja ainda Illich (1990) e o documentário Ser e Vir a Ser (2015)
} 


\section{O trabalho incapacitante}

Illich apontou que as instituições modernas, enquanto parte de um projeto, ao ultrapassarem determinado limiar se tornam prejudiciais à sociedade e levam as pessoas a ser dependentes de seus (des)serviços. Assim, denominou nosso momento histórico "era das profissões incapacitantes", que se caracteriza por uma sociedade que medeia a vida e aliena o trabalho de modo a impossibilitar qualquer projeto de autonomia. Nesta vida, substituímos a política por especialistas e nossas vontades por tecnocratas. Nós mesmos nos tornamos tecnocratas. Para tal, necessitamos viver $1 / 3$ de nossas vidas enclausurados em sistemas escolares que separam o corpo de conhecimentos e incutem-nos necessidades estabelecidas por outrem. Após esse $1 / 3$ de vida, passamos aos $2 / 3$ subsequentes nos quais viveremos não só para produzir, mas também para aumentar nossa própria produtividade. Nesse sentido, o indivíduo se submete aos interesses monopolistas oligárquicos e o crescimento econômico é suportado pela exploração humana e da natureza (ILLICH, 1977a).

O argumento de Illich se baseia na constatação de que a sociedade moderna, apesar de ter um amplo leque disponível de ferramentas tecnológicas, utiliza sua técnica como forma de explorar ainda mais o trabalho. O sonho difundido na primeira metade do século XX de que, dado o tempo, trabalharíamos cada vez menos e teríamos cada vez mais tempo livre, tornou-se uma realidade amarga. No lugar do onirismo libertador, lidamos com uma realidade que transforma toda atividade humana em trabalho, todo ato criador em ato de conformidade. Note-se o atual cotidiano urbano: mesmo o ato culinário e comensal se reduziu ao trabalho. No lugar de famílias comendo em suas casas vemos a ascensão do ato de comer enquanto resultado de um serviço a ser prestado.

Mas não é só isso. Se, por um lado, as classes proletárias urbanas trabalham cada vez menos em indústrias (e o trabalho rural míngua igualmente), por outro, ocorre cada vez mais a criação de procedimentos administrativos. A visão passada de cidades repletas de proletários vestindo macacões industriais dá espaço aos mares de pessoas saindo de e entrando em escritórios, onde passarão o dia produzindo papelada, respondendo e-mails, atendendo telefonemas, seguindo normas e procedimentos, e assim por diante. É o que David Graeber (2018) denomina bullshit jobs: são os atendentes de telemarketing "ativo", os advogados de processos fúteis, os desmotivados gestores de pessoas especializados em motivação, os profissionais de relações públicas que se limitam a "dourar pílulas", os serviços financeiros, os técnicos administrativos que criam camadas de burocracia fútil, e assim por diante. A maioria desses trabalhos não produz, efetivamente, nada - exceto a própria continuidade do trabalho. Além disso, por exemplo, um processo judicial demanda juízes, promotores, outros advogados, peritos etc.; a propaganda de uma empresa exige a resposta da concorrente; as normas administrativas necessitam de mais e mais pessoas para seu cumprimento, e essa lista vai longe (GRAEBER, 2018).

A ironia desse estado de coisas é que, como qualquer economista liberal advogaria, toda relação econômica tenderia à máxima eficiência - e, no entanto, ocorre justamente o oposto. Como um sistema capitalista faz as pessoas produzirem cada vez mais coisas irrelevantes? A resposta, como nota Graeber (2018), não é econômica, mas moral e política. O capitalismo é um projeto de dominação e, enquanto tal, não visa à produtividade maior por si. A produtividade e a riqueza material, central em qualquer discurso liberal desde pelo menos Adam Smith, é um discurso que visa a uma finalidade externa. Graeber (2018) argumenta que as classes dominantes perceberam que uma população feliz e produtiva, com tempo livre em suas mãos, constitui uma ameaça, o que faz do trabalho como valor em si algo extraordinariamente conveniente para elas.

Graeber (2018) percebeu, tal como Illich, que as classes dominantes colocaram em marcha um projeto de deixar a população tão ocupada que sua revolta é impossível. Para o autor, esse projeto se iniciou, ao menos com força, a partir dos anos 1960. Foi uma resposta à contracultura e aos movimentos inconformados - direitos civis nos EUA, Maio de 68 na França. De fato, Graeber (2018) notou que a ética protestante, enquanto conjunto de valores que endeusa o trabalho por si, se mostra incrivelmente útil para as classes dominantes, que passaram a explorar isso à exaustão. Tornou-se a moral dominante crer que aquele que não trabalha à exaustão merece o pior dos destinos - tornamo-nos escravos de nossa própria crença na virtude do trabalho.

Tal como assinalado anteriormente quanto ao "estado de espírito" do subdesenvolvimento e a reificação, em Graeber (2018) também temos uma denúncia do estado das coisas como articulações com fins manipulativos. Ocorre uma objetificação das pessoas, operada em sua transformação em consumidores-especialistas, chegando ao homo miserabilis (ILLICH, 1996), praticamente um oposto ideal ao homem situacionista. No ápice desse projeto, momento presente, reificamos nosso próprio corpo, outorgando-o a especialistas que entendem melhor dele do que nós mesmos. Assim, as transfigurações da noção de saúde assumem papel fundamental, por meio de uma formação corpórea específica. 


\section{Nêmesis da saúde, o tântalo do corpo}

\section{Quando está em jogo a minha saúde, a dona da bola é a Ultrafarma! (ULTRAFARMA, 2018).}

A citação acima, de uma peça publicitária protagonizada por Dunga, ex-futebolista e ex-técnico da Seleção Brasileira e veiculada na televisão aberta brasileira, denota a naturalidade com que a outorga do corpo passou a ocorrer. Publicado originalmente em 1975, A expropriação da saúde: nêmesis da medicina é uma obra central de Ivan Illich na qual o autor demonstra como duas grandes forças que compõem o social - as instituições e o corpo - lutam entre si, com a primeira vencendo em uma sociedade industrial. A saúde, uma propriedade típica do corpo e autônoma do ser, é instrumentalizada em favor de uma instituição. Assim, o argumento central é de que o establishment médico se tornou um perigo para a saúde. A dependência do profissional da saúde destrói relações sociais, constituindo o que Illich denomina "medicamentalização da vida". Tal medicamentalização é a atuação das tecnologias industriais no que há de mais importante na esfera humana: o corpo. Nesse sentido, a medicina moderna, por meio de suas instituições, produz um monopólio radical do uso do aparato médico em detrimento da autonomia do corpo. Ao final, "o monopólio médico [...] é um exemplo flagrante do uso indevido político de conquistas científicas para fortalecer o crescimento industrial em detrimento do crescimento pessoal" (ILLICH, 1975a, p. II).

Para fortalecer seu argumento, Illich ataca em 3 frontes: a) no primeiro, demonstra que aquilo que modernamente consideramos conquistas médicas são, na verdade, conquistas que podem ser atribuídas a outras fontes (como a melhoria da alimentação, da higiene e do saneamento, mais flagrantemente); b) no segundo, demonstra como a saúde institucionalizada destrói relações sociais; e c) no terceiro, argumenta que o corpo não é algo mensurável e que, ao fazer isso, desautonomizamo-nos (ILLICH, 1975a). Em decorrência do primeiro, cria-se a iatrogênese médica, quando procedimentos de saúde desnecessários são imputados aos sujeitos e causam, com frequência, mais problemas do que soluções. Em decorrência do segundo há o conceito de iatrogênese social, que torna o sujeito, e suas relações sociais, um ser passivo diante de uma suposta superioridade técnica da medicina. A iatrogênese social também cria a categoria de doente, com todas as consequências sociais que isso traz. E no terceiro, temos a iatrogênese cultural, ou seja, a substituição de valores autônomos por valores técnicos da instituição de saúde. Abandonam-se as formas culturais de lidar com a dor e a enfermidade para depositar as expectativas em determinada técnica.

A clássica alusão que o filme O Sétimo Selo (1956) faz ao nosso constante jogo de xadrez com a Morte, sendo que todos nós sabemos do desfecho final, transforma-se em um jogo no qual se passa a esperar uma vitória. Dessa forma, o antigo respeito dos médicos e curandeiros a Caronte e sua barca da travessia final cede espaço a uma húbris tecnológica, a uma arrogância diante da morte na qual o corpo humano (alheio a si) é só um meio. Como Illich salienta, enquanto tal batalha ocorre, "“o paciente se torna um objeto residual e, então, um construto tecnológico" (ILLICH, 1995, p. 1652, tradução nossa). No ímpeto de manter sua instituição, a corporação médica atua em uma formação de crenças que impossibilita sua revisão em detrimento da autonomia do paciente. $O$ ser perde a capacidade de, até mesmo, aceitar a morte.

A iatrogênese social e a iatrogênese cultural produziram uma moral e um aparato legal que tornaram impossíveis pequenos atos de autonomia individual, como: a) declarar-se doente para si; b) negar certos tratamentos; c) usar a droga de escolha pessoal; d) ser tratado por uma pessoa (e não só um profissional) de escolha; e e) a liberdade de morrer sem diagnóstico. A eterna busca pela saúde, enquanto técnica institucionalizada, poderia ser considerada uma doença em si. Tal busca nos impede de perceber algumas verdades do corpo: a) nunca eliminaremos a dor; b) nunca curaremos todas as doenças; e c) todos nós morreremos um dia (ILLICH, 1994).

Entretanto, a iatrogênese cultural não é decorrência, propriamente, da medicalização da vida - mas a própria medicalização é decorrência da institucionalização, da profissionalização, da mediação e do uso tecnológico. Os seres se tornam parte de um sistema coordenado onde atuam com base em papéis. Fazemos parte de uma ecologia populacional na qual o sistema médico não é apenas um esquema de diagnóstico e tratamento, mas também um conjunto de regras para "otimização da vida". O sistema funcional, enquanto uma grande população coordenada e administrada, incorpora a vida em todos os aspectos (ILLICH, 1995). O projeto da instituição saúde é transformar, ao final, o corpo em informação, ou seja, descorporificar por meio da dependência à medicalização. Ao final, tornamo-nos informação no mar de uma memória infinita. Não somos mais mortais ou imortais, mas amortais, pois perdemos a capacidade até da morte - ou da vida (ILLICH, 1974a). 


\section{Era dos sistemas}

Chicago, 1964. Em meio ao vozerio indefinido de um auditório em preparação para uma palestra que daria com outros professores, Ivan Illich estava sentado em uma mesa e conversava com um jovem antropólogo. No momento culminante da conversa, o jovem disparou: "Illich, você não consegue me envolver, não consegue se comunicar comigo!". Tal como muitos dos jovens universitários da atualidade, ele estava reclamando da falta de performatividade de Ivan. A seu ver, o professoral Illich deveria prender sua atenção tal como um filme. Depois de um momento de desconcerto, Illich se enfureceu. O motivo, percebeu anos depois, foi que ali, pela primeira vez na sua vida, alguém the dirigia a palavra como se fosse um receptortransmissor. Ou seja, uma pessoa viva, com quem julgava estar dialogando, considerava sua fala algo muito mais impessoal, como se fosse uma interface cibernética incapaz de gerar alteridade (ILLICH, 1990).

Essa cibernética, temática que Illich abordou em sua obra tardia, visualiza-se em um grande sistema social que, por meio de ferramentas manipuláveis, torna todos nós partes de um grande conjunto industrial manipulativo. $O$ ápice dessa heteronomização social, que até então se dava por meio de instituições, passa a ocorrer por meio de um sistema social integrado totalizante.

Essa problematização de Illich encontra seu cerne na questão do corpo, explorada em sua obra a partir da década de 1980. Como notam alguns de seus intérpretes, como Nogueira (2003), Illich passa a ecoar a noção de corpo encontrada nas obras de Michel Foucault. Para Illich, o corpo é o lócus da experiência e, portanto, dá-se na relação entre a carne e o contexto. Assim, aquilo que chamamos de corpo ("meu corpo") é o corpo experienciado. Por exemplo, o corpo atual, enquanto reflexo de uma sociedade industrial, é "fretável", transportável enquanto mercadoria, o que seria uma concepção absurda para um habitante de séculos anteriores. "Manuais de engenharia falam de 'auto-transporte' quando andamos a pé ao invés de usar um elevador. E nos sentimos [...] privados de algo se temos de caminhar" (ILLICH, 1986, p. 1326). O corpo real é o corpo experienciado nas condições materiais de seu momento histórico e de seu lugar. Dessa forma, Illich transita no argumento do corpo iatrogênico para o corpo fabricado pelo sistema social para atuar no próprio sistema. Quando argumentou contra a institucionalização da saúde, Illich (1975a) percebeu que o corpo era experienciado como resultado da intervenção médica, o que denomina corpo iatrogênico. Até ao negar tal instituição se iatrogeniza o corpo: "two apples a day keeps the doctor away" ("duas maçãs por dia mantêm o médico longe") diz o ditado britânico até hoje popular.

Tal argumento, produzido a partir de seu livro "A expropriação da saúde" de 1975, é confrontado com um mundo em mudança. Ao final dos anos 1980, Illich percebeu que havia algo se alterando no contexto da produção dos corpos. Do corpo como resultante industrial (o corpo iatrogênico), o autor nota que tal medicina passa a ser internalizada, tal qual a própria produção industrial. Assim, Illich argumenta que o corpo do humano ocidental não era mais o iatrogênico, mas produzido por nós mesmos com base na maneira sistêmica de conceber o mundo.

A outorga do corpo ao profissional da saúde deu espaço à outorga do corpo a uma neurose de saúde. Internalizamos o profissional e passamos a incorporar a opinião médica em nossas práticas cotidianas. Reificamos nosso próprio corpo, tornando-o secundário a nós mesmos (presumindo que isso é possível). Da mesma forma que nossa sociedade é uma massa reificada administrável, separamos nosso corpo de nossa mente, passando a administrá-lo. Assim, o corpo não é mais reduzido ao ser passível da interferência médica, não é mais o corpo iatrogênico, mas um corpo administrável, produzível, moldável. "De um empreendimento que reifica as pessoas como psiques e corpos, um novo modelo surgiu que engendra pessoas que reificam a si mesmas: os que se concebem como 'produtores' do seu próprio corpo" (ILLICH, 1992, p. 217). Senão, note-se: o corpo passou a ser parte, mesmo em escritos acadêmicos, de um mundo "material" em oposição a um mundo "imaterial”. Dessa forma, temos o trabalho corporal, que passa a ser denominado material, e um trabalho "imaterial", que é apenas uma forma absurda de colocar o corpo em segundo plano e legitimar a reificação e exploração do trabalho. Nesse processo, passamos a nos tornar partes sistemáticas e cibernéticas de um corpo social, internalizando as funções sociais em nós mesmos.

Tal conceituação remonta a um estruturalismo funcionalista. Por um lado, tudo tem de fazer parte de um esquema bem montado e modelado de realidade - a estrutura formal. Por outro lado, cada parte dessa estrutura tem de ter sua função tal como o corpo com seus órgãos, onde "o conjunto das crenças e dos sentimentos comuns à média dos membros de uma mesma sociedade forma um sistema determinado que tem vida própria", forma uma "consciência coletiva", um corpo social (DURKHEIM, 1977, p. 50). 


\section{SUBJETIVAÇÃO DA VIGILÂNCIA EM MASSA}

Se reificamos o corpo em prol de um sistema social coeso que busca constantemente uma homeostase por meio de seus órgãos funcionais profissionalizados, o computador, a internet e os meios de comunicação mais correntes são formas máximas de operacionalizar isso. A intuição de Illich era de que estava em ascensão desde a década de 1980 uma "personalidade cibernética", o que desloca a crítica para uma posição mais radical. Ao se integrarem em um texto cibernético, as instituições sociais passaram a comportar pessoas com um novo espaço mental correspondente. Assim, o problema não é que a escola impede a instrução, mas que sua existência denota um sistema onde a segregação social a tornou necessária. Portanto, a crença na necessidade de ser instruído nada mais é do que a consequência da degradação dos meios necessários à socialização (ILLICH, 1990, p. 18).

Com a personalidade cibernética, a separação entre usuário e ferramenta ${ }^{8}$ se perde e passamos a nos controlar. 0 que pode soar como uma utopia é a formação de uma subjetividade policialesca total em níveis até pouco tempo inimaginados, como aponta Samerski (2018, p.18, tradução nossa):

Com a ascensão de um novo regime governamental ao redor da "segurança", bem como com técnicas estatísticas refinadas e poder computacional automatizado, cidadãos têm cada vez mais sido tratados como casos estatísticos, como perfis de risco sem rosto. As pessoas não são governadas com relação às suas individualidades ou identidades, mas como membros de uma população. O indivíduo incorporado é de interesse do governo apenas conquanto possa ser identificado, categorizado e reconhecido como um membro de uma população.

Para se sentir seguros, os habitantes do corpo da personalidade cibernética têm constante necessidade de vigilância e controle. Não podem mais confiar em seus sentidos e encarnam, literalmente, a necessidade de autovigilância e controle. Em um segundo momento, todos se tornam suspeitos (SAMERSKI, 2018).

Isso retoma a ideia de fascismo gerencial dos primeiros textos de Illich, na década de 1970. Trata-se da ideia de introjetar, por meio de cooptação ou de um sequestro da subjetividade dos indivíduos, os valores e ideais da empresa em seus integrantes, quais sejam, da maximização da eficiência e da manutenção da segurança e da ordem. Nesse sentido, os aplicativos de corrida, as publicações de visitas a determinados locais (check-ins, stories e outros posts) e as demais formas de reportar a vida pessoal reforçam um controle mútuo e quantificam as vidas de modo a atingir uma onipresença da competição e da concepção de risco, que leva ao esgotamento, ao medo, à ansiedade e à depressão.

\section{CONSIDERAÇÕES FINAIS}

Este artigo parte da introdução do conceito de desequilíbrio institucional e como este deriva de uma categoria analítica baseada na ideia de ferramenta de Ivan Illich. Para o autor, separam-se as ferramentas manejáveis e manipuláveis. A primeira se refere àquelas em que toda energia requerida para seu uso advém do usuário. Já a segunda é a ferramenta que se utiliza de uma energia externa ao ser humano, ao menos boa parte dela. Se a primeira pode ser ilustrada com a pua, a segunda se torna a furadeira. Quanto mais complexo se torna o repertório de ferramentas manipuláveis, maior a tendência das ferramentas se tornarem uma caixa-preta, o que exclui a possibilidade do devir e da ação criativa.

Assim, passado determinado limiar, o conjunto de ferramentas manipuláveis captura as ferramentas manejáveis. Com isso, abre-se o "reino das manipulações", onde as ferramentas se tornam manipulativas, onde a relação de uso se inverte: o humano, e não a ferramenta, torna-se meio para um fim.

O arcabouço de ferramentas é, no pensamento de Illich, o que compõe o cerne das instituições. Uma vez que este se tornou manipulativo, a raison d'être das instituições se torna uma legitimação tautológica. A partir desse ponto, traçamos o caminho da crítica da institucionalização e sua progressiva intensificação, que culmina em uma mudança estrutural da sociedade, tornando o conjunto de instituições uma grande máquina cibernética.

\footnotetext{
${ }^{8}$ A separação entre usuário e ferramenta compõe um conceito central para Ivan Illich. Trata-se da "distalidade", que surge com a era das ferramentas (final da Idade Média), e que possibilita que a técnica seja utilizada em proveito do usuário.
} 
Em outras palavras, apresentamos como a era das ferramentas se tornou a era dos sistemas por meio das instituições. As obras clássicas dos anos 1970 de Illich, que enfocam em instituições específicas (escola, trabalho e medicina), constituem o que o autor denominou "sistema" em sua obra tardia. Uma consequência disso é que o corpo iatrogênico, dependente da instituição médica, torna-se o corpo cibernético, totalmente desincorporado. Esse corpo, nosso corpo, é parte operante do corpo com órgãos, funcionalista, que torna possível uma era dos sistemas.

No quarto capítulo, partimos para a ilustração do problema cibernético. Para tal, tratamos de como os sistemas de vigilância em massa, objetos tão presentes na atualidade, decorrem da topografia mental da era dos sistemas. Nesse sentido, a era dos sistemas é o momento histórico que atravessamos, onde a predominância de ferramentas manipulativas se aprofunda pela integração das instituições e nos tornamos sub-sistemas do sistema social, a vida se torna um sistema imunológico e o próprio planeta é visto como um ecossistema. Introjetamos os papéis que desempenhamos no sistema em tempo integral. Tornamo-nos o Bloom de Tiqqun (2010), tornamo-nos no não-ser, num pot-pourri de papéis a serem exercidos, de subjetividade cooptada pelo sistema. Mas o pensamento de Illich possibilita uma gama de outras reflexões e aplicações, de modo que só tratamos de uma das possíveis.

Como salienta Agamben (2013a, p. 9), em todas as pesquisas de Illich está presente a noção de uma ameaça ao caráter humano. Essa ameaça se visualiza enquanto o projeto moderno de tornar todos em seres necessitados, no homo miserabilis de Illich. A oposição a isso, pretendida por Illich, era da formação de uma sociedade convivial baseada no homem habilidoso, autônomo, situacional, que combina o predomínio das ferramentas manejáveis com o uso comum do ambiente, por meio dos commons. A convivialidade, nesse sentido, não é uma proposição meramente organizacional: ela reflete um projeto de sociedade por meio de uma proposição de ser humano.

Podemos encontrar outras ricas reflexões contemporâneas que dialogam diretamente com a obra de Illich sobretudo no trabalho de Giorgio Agamben. O filósofo italiano retoma a ideia da Era das Ferramentas em sua arqueologia do dever (AGAMBEN, 2015a). Também, baseando-se no significado que Illich (ILLICH apud CAYLEY, 2005) atribui ao conceito teológico mysterium iniquitatis, vislumbra a institucionalização da igreja católica como pedra basilar do Estado moderno e da crise da atualidade (AGAMBEN, 2015b, 2013a). Outros trabalhos de Agamben incluem noções illichianas para elaborar sobre a constituição da zoé como vida política (2017), pensar a necessidade de um poder destituinte (2014) e rumo a uma biopolitica menor (2016).

De fato, Illich tem se mostrado um autor relevante e em crescente uso. Parece-nos aquilo que Friedrich Nietzsche chamava de "autor póstumo": seus pensamentos só seriam apreciados após seu tempo de vida. Desde sua morte, em 2002, o pensamento de Illich tem permeado diversos movimentos, inclusive sendo utilizado na área de estudos organizacionais. Pansera e Rizzi (2018) se apropriam do pensamento de Illich para pensar como cooperativas sociais podem constituir um vislumbre pós-capitalista. Já Vieta (2014) utiliza o pensamento de Illich, em conjunção com Murray Bookchin e Herbert Marcuse, para aprofundar o pensamento de Proudhon (1989) e Mikhail Bakunin e prefigurar organizações. Bialski, Derwanz, Otto et al. (2015) demonstram como Illich foi relevante para a constituição do pensamento do decrescimento. Já Swann (2018) afirma que o pensamento de Illich foi constitutivo na crítica presente do movimento Critical Management Studies (Estudos Críticos da Administração, em tradução livre). Martin Parker (2018) ecoa as críticas de Illich à universidade (DUNNE, HARNEY, PARKER et al., 2008) e, em particular, às escolas de administração. Armstrong (2013), por sua vez, utiliza-se da ideia de profissões incapacitantes para estudar o consumo. No Brasil, algumas contribuições já foram feitas, por exemplo as de Daher e Seifert (2017), Leão Neto (2017), Leonídio e Leão Neto (2019), Casagrande (2018) e Freitas (2019). Em Singh (2017) podemos observar uma questão para além do que foi tratado neste artigo, ao trazer a ideia de commons de Illich para refletir sobre a vida convivial. Reichel (2017) utiliza o pensamento illichiano para pensar as organizações em um mundo de pós-crescimento. De fato, o mesmo autor, no ano seguinte, assina a chamada do periódico Organization, amparada em Illich, para pensar a sociedade pós-crescimento (BANERJEE, JERMIER, PEREDO et al., 2018).

As primeiras décadas do século XXI já deixam claro que temos novos e grandes desafios pela frente, como a mudança climática, o autoritarismo e a desigualdade social. Entendemos que a leitura de Ivan Illich apresenta um grande potencial para os anos vindouros e o pensamento desse autor possibilita a construção de uma agenda de pesquisa que aborde, por exemplo: a) as relações entre tecnologia, sociedade e organizações; b) as organizações na sociedade de vigilância e risco; c) o decrescimento; e d) os modos alternativos de organizar a partir da noção de convivialidade. 


\section{REFERÊNCIAS}

AGAMBEN, G. Introduzione. In: ILLICH, I. Gender. Per Una Critica Storica Dell'Ugualianza. Vicenza: Neri Pozza, 2013a.

AGAMBEN, G. Por uma teoria do poder destituinte. Atenas: Instituto, 2014. Disponível em: <https://5dias.wordpress.com/2014/02/11/ por-uma-teoria-do-poder-destituinte-de-giorgio-agamben/>. Acesso em: 7 out. 2018.

AGAMBEN, G. Opus dei: Arqueologia do ofício [Homo Sacer, II, 5]. São Paulo: Boitempo Editorial, 2015a.

AGAMBEN, G. O Mistério do Mal: Bento XVI e o fim dos tempos. 1. ed. São Paulo: Boitempo ; Florianópolis: Ed. da UFSC, 2015b.

AGAMBEN, G. Uma Biopolítica Menor. São Paulo: N-1 Edições, 2016. AGAMBEN, G. O Uso dos Corpos [Homo Sacer, IV, 2]. São Paulo: Boitempo Editorial, 2017.

ARMSTRONG, P. Alienated consumption, the commodification of taste and disabling professionalism. Ephemera: Theory and Politics in Organization, v. 13, n. 2, p. 269-292, 2013.

BANERJEE, B. et al. Call for papers for a special issue of Organization: theoretical perspectives on organizations and organizing in a postgrowth era. Organization. 2018. Disponível em: <https://journals. sagepub.com/pb-assets/cmscontent/ORG/SI\%20Organization\%20 Degrowth\%20(2).pdf>. Acesso em: 27 nov. 2018.

$B E Y, H$. Fé midiática de fim de século. In: BEY, H. Sobre a anarquia. Porto Alegre: Deriva, 2008. p. 27-41.

BIALSKI, P. et al. 'Saving' the city: collective low-budget organising and urban practice. Ephemera: Theory and Politics in Organization, v. 15, n. 1, p. 1-19, 2015.

CASAGRANDE, L. O Poliencantamento do Mundo por meio das Organizações Imediatistas. 151f. 2018. Tese (Doutorado em Administração) - Escola de Administração, Programa de Pós-Graduação em Administração, Universidade Federal do Rio Grande do Sul, Porto Alegre, 2018.

CAYLEY, D. (Ed.). The Rivers North of the Future: The Testament of Ivan Illich as told to David Cayley. Toronto: House Of Anansi Press, 2005.

CODELLO, F. “A Boa Educação”: Experiências Libertárias e Teorias Anarquistas na Europa, de Godwin a Neill. Vol. 1: A Teoria. São Paulo: Imaginário, Ícone, 2007.

COOKE, B. The managing of the (third) world. Organization, v. 11, n. 5, p. 603-629, 2004.

DAHER, S.; SEIFERT, R. E. Gênero em organizações convivenciais: possibilidades de um espaço de redistribuição, reconhecimento e representação. In: COLÓQUIO INTERNACIONAL DE EPISTEMOLOGIA E SOCIOLOGIA DA CIÊNCIA DA ADMINISTRAÇÃO, 6., 2017, Florianópolis. Anais... Florianópolis: Universidade Federal de Santa Catarina, 2017.

DEBORD, G. Manifesto internacional situacionista. 2011. Disponível em: <https://pt.protopia.at/wiki/Manifesto_Internacional_Situacionista>. Acesso em: 12 abr. 2015.

DUNNE, S. et al. Discussing the role of the business school. Ephemera: Theory and Politics in Organization, v. 8, n. 3, p. 271-293, 2008.
DURKHEIM, E. Da divisão do trabalho social. São Paulo: Martins Fontes, 1977.

ESTIMADO, R. B.; SANTOS, J. L. L. P. Limites e possibilidades da educação formal: um debate entre Paulo Freire e Ivan Illich. Humanidades em Diálogo, n. 6, p. 175-190, 2014.

FAURE, S. A Colmeia: Uma Experiência Pedagógica. São Paulo: Biblioteca Terra Livre, 2015.

FREIRE, P. Apresentação. In: HARPER, B. et al. Cuidado, escola! Desigualdade, domesticação e algumas saídas. São Paulo: Brasiliense, 1980. p. 7.

FREIRE, P. Pedagogia do oprimido. 17. ed. Rio de Janeiro: Paz e Terra, 1987.

FREITAS, N. C. Ferramentas Organizacionais da Convivialidade: Aproximações de Ivan Illich aos Estudos Organizacionais. 106 f. 2019. Dissertação (Mestrado em Administração) - Escola de Administração, Programa de Pós-Graduação em Administração, Universidade Federal do Rio Grande do Sul, Porto Alegre, 2019.

GRAEBER, D. Bullshit jobs: a theory. London: Simon \& Schuster, 2018.

GUERREIRO RAMOS, A. A nova ciência das organizações. 2. ed. Rio de Janeiro: Fundação Getúlio Vargas, 1989.

ILLICH, I. Tools for conviviality. New York: Harper \& Row, 1973a.

ILLICH, I. La convivialité. Paris: Seuil, 1973b.

ILLICH, I. Medical nemesis. The Lancet, v. 303, n. 7863, p. 918-921, 1974a.

ILLICH, I. La convivencialidad. Barcelona: Barral, 1974b.

ILLICH, I. La convivialità. Milano: Arnoldo Mondadori, 1974c.

ILLICH, I. A Expropriação da Saúde: Nêmesis da Medicina. Rio de Janeiro, Nova Fronteira, 1975a.

ILLICH, I. Escola, esta vaca sagrada. In: ILLICH, I. Celebração da consciência. Petrópolis, RJ: Vozes, 1975b.

ILLICH, I. Vigor sexual e poder político. In: ILLICH, I. Celebração da consciência. Petrópolis, RJ: Vozes, 1975c.

ILLICH, I. A Convivencialidade. Lisboa: Publicações Europa-América, 1976.

ILLICH, I. Disabling professions (ideas in progress). London: Marion Boyars, 1977a.

ILLICH, I. Outwitting developed nations. In: ILLICH, I. Toward a history of needs. Berkeley, CA: Heydey, 1977b.

ILLICH, I. Body history. The Lancet, v. 328, n. 8519, p. 1325-1327, 1986.

ILLICH, I. Na ilha do alfabeto. In: ILLICH, I. Educação e liberdade. São Paulo: Imaginário, 1990. p. 21.

ILLICH, I. Twelve years after medical nemesis. In the mirror of the past, lectures and addresses, 1978-1990. New York: Marion Boyars, 1992.

ILLICH, I. Health as one's own responsibility: no, thank you! Journal of Consciousness Studies, v. 1, n. 1, p. 25-31, 1994. 
ILLICH, I. Death undefeated: from medicine to medicalisation to systematisation. British Medical Journal, v. 311, n. 7021, p. 16521653, 1995.

ILLICH, I. Necessidades. In: SACHS, W. (Ed.). Diccionário del desarollo: un guía del conocimiento como poder. Lima: Pratec, 1996. p. 144-163.

ILLICH, I. Energia e equidade. In: LUDD, N. (Org.). Apocalipse motorizado: a tirania do automóvel em um planeta poluído. São Paulo: Conrad, 2005. p. 33-72.

ILLICH, I. Sociedade desescolarizada. Porto Alegre: Deriva, 2007.

ILLICH, I. Sociedade sem escolas. Petrópolis, RJ: Vozes, 2018.

ILLICH et al. Educação e Liberdade. São Paulo: Imaginário, 1990.

LATOUCHE, S. Será o decrescimento a boa nova de Ivan Illich? São Leopoldo, RS: Instituto Humanitas Unisinos, 2012. (Cadernos IHU Ideias, ano 10, n. 164).

LEÃO NETO, E. P. S. Ivan Illich: uma aproximação com sua trajetóriaobra (1926-1967). 117 f. 2017. Dissertação (Mestrado em Ecologia Aplicada) - Ecologia de Agroecossistemas, Universidade de São Paulo, Piracicaba, 2017.

LEONIDIO, A., LEÃO NETO, E. P. S. A Utopia de Ivan Illich. Diálogos Latinoamericanos, v. 20, p. 30-40, 2019.

MARCUSE, H. One-dimensional man: studies in the ideology of advanced industrial society. 2. ed. Boston: Beacon Press, 1991.

MARSDEN, R.; TOWNLEY, B. Introdução: a coruja de Minerva - reflexões sobre a teoria na prática. In: CLEGG, S. R.; HARDY, C.; NORD, W. R. (Orgs.). Handbook de estudos organizacionais. São Paulo: Atlas, 2001. v. 2, p. 31-60.

MESQUIDA, P. O diálogo de Illich e Freire em torno da educação para uma nova sociedade. Contrapontos, v. 7, n. 3, p. 549-563, 2007.

MILANA, F. Ivan Illich, cronologia della vita. In: ILLICH, I. Pervertimento del cristianesimo. Macerata: Quodlibet, 2008. p. 123-148.

NOGUEIRA, R. P. A segunda crítica social da saúde de Ivan Illich. Interface: Comunicação, Saúde, Educação, v. 7, n. 12, p. 185-190, 2003.

ORWELL, G. 1984. São Paulo: Claro Enigma, 2010.

O SÉTIMO SELO. Direção: Ingmar Bergman. Estocolmo: Svensk Filmindustri, 1956. 1 DVD (96 min), son., P\&B.
PANSERA, M.; RIZZI, F. Furbish or perish: Italian social cooperatives at a crossroads. Organization, p. 1-19, 2018. Disponível em: <https:// doi.org/10.1177/1350508418760980>. Acesso em: 12 abr. 2015.

PARKER, M. Shut down the business school. Chicago: University of Chicago Press, 2018.

PROUDHON, P. J. General idea of the revolution in the nineteenth century. London: Freedom Press, 1989.

REICHEL, A. Shape of things to come: from the 'laws of form' to management in the post-growth economy. Ephemera: Theory \& Politics in Organization, v. 17, n. 1, p. 89-118, 2017.

SAMERSKI, S. Individuals on alert: digital epidemiology and the individualization of surveillance. Life Sciences, Society and Policy, v. 14, n. 1, p. 13, 2018.

SER E VIR A SER. Produção de Clara Belar. Realização de Clara Belar. Roteiro: Clara Belar. [s.I]: Pourquoi Pas Productions, 2015. (99 min.), DVD, son., color. Legendado.

SILVA, G. C. E. A polêmica Paulo Freire e Ivan Illich: notas sobre educação e transformação. Revista Sul-Americana de Filosofia e Educação, n. 24, p. 102-120, 2016.

SINGH, N. Becoming a commoner: the commons as sites for affective socio-nature encounters and co-becomings. Ephemera: Theory \& Politics In Organization, v. 17, n. 4, p. 751-776, 2017.

SWANN, T. Towards an anarchist cybernetics: Stafford Beer, selforganisation and radical social movements. Ephemera: Theory and Politics in Organization, v. 18, n. 3, p. 427-456, 2018.

TIQQUN. Bloom Theory. 2018. Disponível em: <https:// theanarchistlibrary.org/library/tiqqun-bloom-theory>. Acesso em: 20 jul. 2018.

TRAGTENBERG, M. A delinquência acadêmica. Verve: Revista Semestral Autogestionária do Nu-Sol, n. 2, p. 175-184, 2002.

ULTRAFARMA. Ultrafarma com Dunga e Gilmar Rinaldi. 2018. Disponível em: $<$ https://www.youtube.com/watch?v=9qNE305VmQE $>$. Acesso em: 11 dez. 2018.

VIETA, M. The stream of self-determination and autogestión: prefiguring alternative economic realities. Ephemera: Theory and Politics in Organization, v. 14, n. 4, p. 781-809, 2014.

Lucas Casagrande

ORCID: https://orcid.org/0000-0002-8327-4810

Doutor em Estudos Organizacionais pela Universidade Federal do Rio Grande do Sul (PPGA-UFRGS); Professor da Escola de Administração da Universidade Federal do Rio Grande do Sul (EA-UFRGS), Porto Alegre - RS, Brasil. E-mail: Lucas.Casagrande@ufrgs.br

Nilo Coradini de Freitas

ORCID: https://orcid.org/0000-0002-2327-8297

Mestre em Estudos Organizacionais pela Universidade Federal do Rio Grande do Sul (PPGA-UFRGS), Porto Alegre - RS, Brasil. E-mail: nilof@tutanota.com 